\title{
Slow Recovery to Nowhere? Labor Market Issues in Advanced Economies: Introduction
}

\author{
Nauro Campos ${ }^{1,2} \cdot$ Karim El Aynaoui ${ }^{3}$ Davide Furceri ${ }^{4}$. \\ Prakash Loungani $^{5}$
}

A decade ago, the world faced the prospect of the next Great Depression. The worst did not come to pass. In the 1930 s, the unemployment went up to $25 \%$ in some countries. This time the average unemployment rate for advanced economies did increase sharply to over $8 \%$ in 2010 from $5 \frac{1}{2} \%$ in 2007 but has since slowly returned to its level before crisis, as shown in Fig. 1 (International Jobs Report 2017).

The situation in labor markets is thus better than a decade ago but it is far from nirvana. This special issue contains papers that describe:

- some of the strains in labor markets that existed prior to the global financial crisis (GFC);

- how developments in the run-up to the GFC and the legacies of the crisis can affect labor markets in the years to come;

- the impacts of longer-run trends such as automation and sectoral transformation.

The issue concludes with some evidence on the effectiveness of structural reforms, often offered as a panacea for what ails labor markets and the economy.

Prakash Loungani

PLOUNGANI@imf.org

1 Brunel University (London), London, UK

2 ETH-Zurich, Zürich, Switzerland

3 OCP Policy Center and Mohammed VI Polytechnic University, Ben Guerir, Morocco

4 IMF and University of Palermo, Palermo, Italy

5 IMF and Vanderbilt University, Nashville, TN, USA 


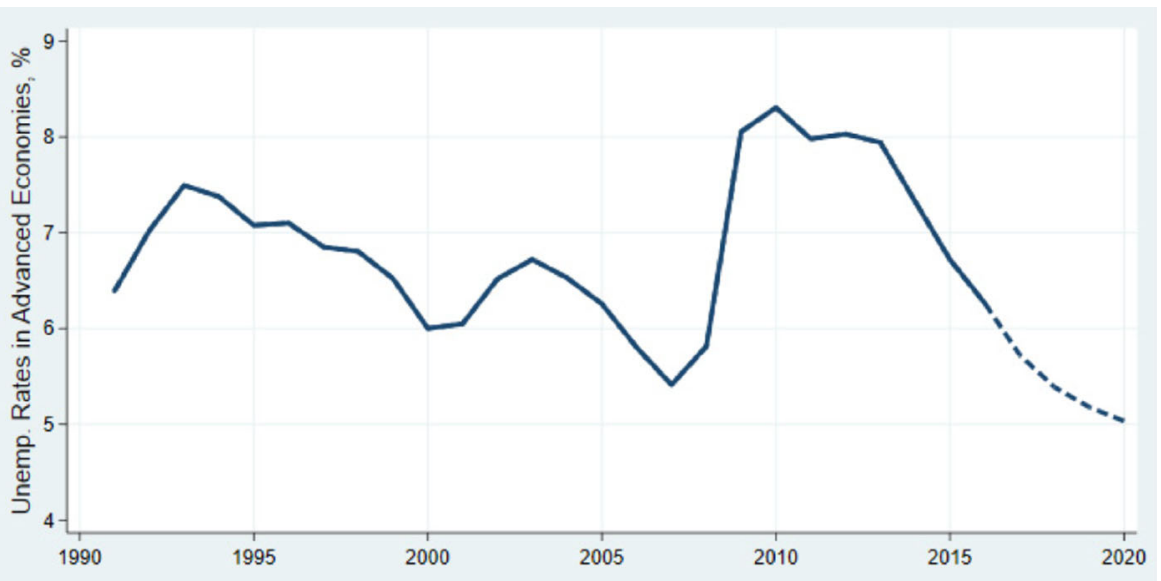

Fig. 1 Unemployment Rate in Advanced Economies. (averaged across 37 economies). Source: International Jobs Report, OCP Policy Center (see July 3, 2017 edition for details on the construction of the unemployment rate). The dashed line is the forecasted path based on IMF forecasts

\section{Nominal Convergence Breeds Real Divergence?}

Since the Maastricht Treaty in 1992, many European countries have been on a path of economic integration. This brought about a remarkable convergence in inflation rates. But outcomes in the labor market, such as unemployment, have diverged across countries, as demonstrated by Monfort et al. (2018; this issue). Using cluster analysis, ${ }^{1}$ they show that unemployment rates in countries like France and Spain have been on a different transition path than countries like Denmark and the Netherlands. Withincountry inequalities in income have also remained high and further diverged across countries. They conclude that "the promotion of cohesion, which was one of the declared objectives of the European Union, has largely failed."

Divergence also has also persisted, and may even have widened, in the access of individuals to good quality education: for instance, "there is not one channel of higher education, but two: graduating from a prestigious university, or graduating from a standard university or local college," write Brezis and Brand (2018; this issue). ${ }^{2}$ The authors show that the tradable sectors of economies, which have higher productivity levels than non-tradable sectors, also tend to employ people who do better on cognitive tests - more likely to be those who have graduated from a prestigious university - than those employed in the non-tradable sector. This is illustrated in Fig. 2 for the Israeli economy - the distribution of scores for those in tradables is sharply skewed to the right compared to that for nontradables.

This raises the intriguing possibility, which deserves greater investigation, that productivity gaps between the two sectors may not be the result just of greater global competition in the tradable sectors, or of intrinsic differences in the nature of the

\footnotetext{
${ }^{1}$ The analysis uses the panel data model of Phillips and Sul (2007).

${ }^{2}$ Brezis and Hellier (2018) present suggestive evidence that such a dual higher-education system "generates permanent social stratification, high social immobility and self-reproduction of the elite."
} 

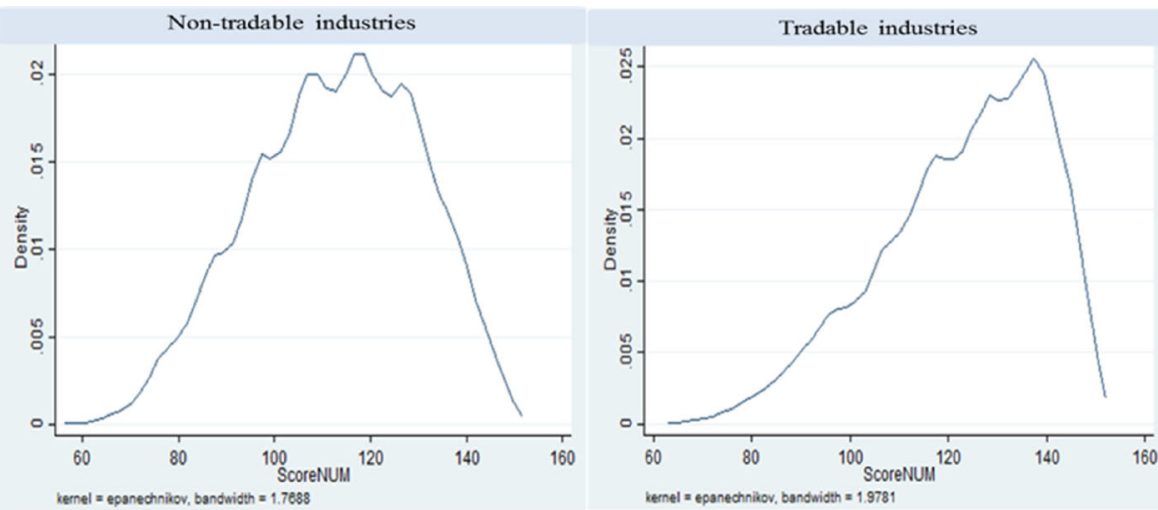

Fig. 2 Distribution of cognitive scores in non-tradable and tradable industries. Source: Brezis and Brand (2018). The distribution of scores for the Israeli economy for 2011 on a cognitive test equivalent to an SAT exam. The distribution of PIACC scores for 23 OECD countries shows a similar pattern on average

sectors, but due to differences in workers' abilities, which is in turn partly determined by access to good quality education.

Another long-standing divergence in labor markets is that between workers in the formal and informal sectors. Informality is so rife in so many economies that it has prompted the slogan "informal is normal". As Petreski (2018; this issue) notes, there are two views about the impact of informality on an individual's labor market prospects. One is that informality provides networks and working attitudes that help workers, particularly young workers, make the transition to formal sector jobs. The other is that workers who start out in informal sector jobs end up with a stigma that mars their future labor market performance. Using a new survey data set on school to work transitions, Petreski shows that for the economies of southeast Europe and the former Commonwealth of Independent States that informality early on in the career has negative impact on later labor market outcomes such as wages and odds of finding a decent job in the formal sector. ${ }^{3}$

\section{Legacies of the Global Financial Crisis}

The global financial crisis exacerbated many of these divergences in labor markets. For instance, unemployment shot up across Europe but much more in Spain than in Germany. What should we expect as the recovery proceeds? Hantzche et al. (2018; this issue) find, using industry-level data for 15 euro area countries since 1999, that in the past labor markets have displayed an asymmetric response to downturns and upturns. During a downturn, employment and real wages fall, with the relative adjustment depending on the extent of employment protection in each sector. For instance, more of the response occurs through real wages in the services sector than in

\footnotetext{
${ }^{3}$ Petreski notes that, in contrast, the evidence from Latin America suggests that informal jobs for young workers served as a stepping stone for their future careers. See Stuart et al. (2018) for an excellent discussion of the extent of informality in economies and steps to improve the lives of people who are likely to remain in the informal sector for a long time.
} 
manufacturing. In contrast, much of the initial response during the upturn occurs through an increase in hours worked per worker rather than in employment or real wages. If past is prologue, we should thus expect a slow recovery in employment and real wages, once companies have exhausted the potential to adjust through the hours margin.

Can the recovery in house prices help labor markets? After a steep fall, housing markets have recovered, as shown in Fig. 3: the IMF's Global House Price Index-an average of house prices in 57 economies - has inched back to its level before the GFC, though the extent of the recovery differs across markets (Ahir and Loungani 2016).

The theoretical and empirical analysis by Ernst and Saliba (2018; this issue)-using a standard DSGE model extended to allow for a rich set of interactions between labor and housing markets - sheds some light on this question. They show that while housing booms can provide a short-lived boost to growth and employment, as indeed happened during the 2003-07 global boom in housing markets, the longer-lasting effects can actually be negative. Their model and empirical results point to some channels through which these negative effects occur. One channel is through a decline in aggregate productivity as an increasing share of the economy's resources get allocated to the construction sector during the housing boom. House prices also ultimately feed through into higher wage costs and capital costs (particularly if the house price boom is accompanied by increases in commercial property prices). In short, while the recovery in housing markets from the doldrums is welcome, it seems better not to rely excessively on housing markets as a source of economic stimulus.

\section{A Grave New World in Labor Markets?}

A couple of papers in the special issue have implications for thinking about the impacts of longer-term developments in labor markets such as the changes in the sectoral allocation of labor towards services and the impacts of automation.

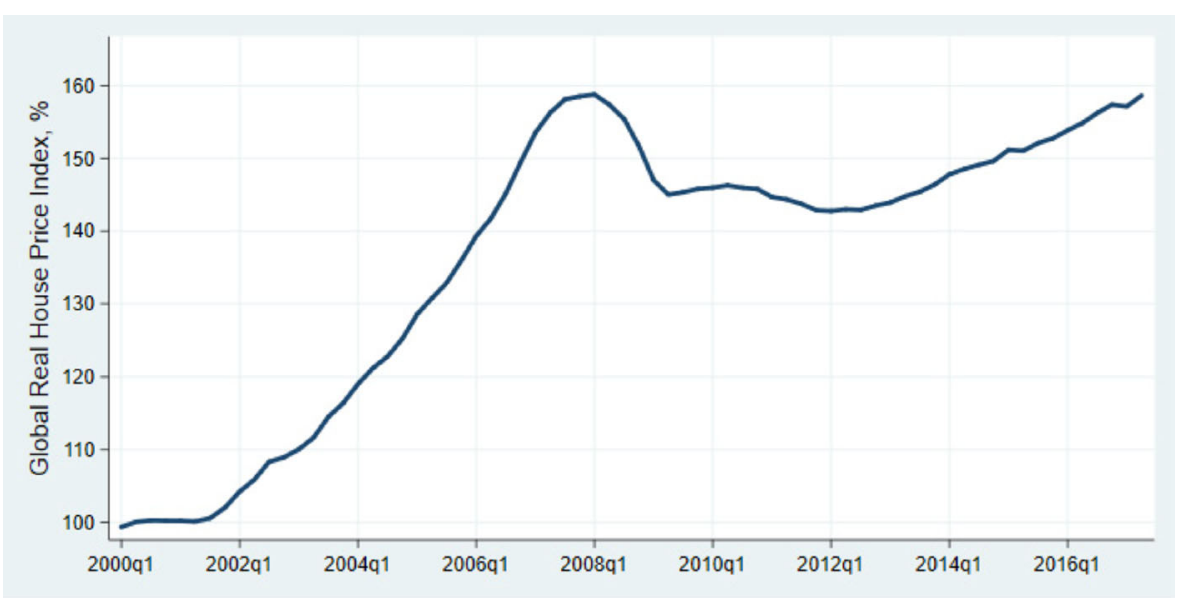

Fig. 3 IMF Global House Price Index. (average across 57 economies). Source: IMF Global Housing Watch. See Ahir and Loungani (2016) for details 
The vast majority of employment in the advanced economies is now in service sector industries. Productivity increases in this sector are difficult to achieve but they are thought to be less cyclically sensitive, hence buffering labor markets from the impacts of downturns. Gonzalez Prieto, Loungani and Mishra (2018; this issue) present evidence questioning the latter view. They show that, for the United States at least, while some service sectors like health care are indeed fairly recession-proof, others like professional and business services are almost as cyclical as manufacturing; employment in financial activities and in trade, transportation and utilities is also fairly cyclical. This is shown in Fig. 4, which reports the elasticity of employment growth with respect to GDP growth for various sectors.

The authors also show that the cyclical sensitivity of some service industries may be part of the reason that Okun's Law has remained stable over the past five decades despite the shift in employment away from manufacturing towards services. The mild impact on labor markets during the downturns of the 1990s and 2000s (prior to the Great Recession) may have been due not to the buffering effects of the service sector but due to the recessions themselves being fairly mild.

Another trend much in the news is automation. The fear that robots will take away jobs is pervasive. As Chen and Semmler show, for the United States from 1950 to the present, there is a clear distinction between the short-run and long-run relationship between productivity and unemployment. In the short-run, an increase in productivity has a small and not very precisely measured increase in unemployment. In the long-run, an increase in productivity leads to a much larger and precisely measured reduction in unemployment. Figure 5 illustrates the striking difference: the correlation between the long-run components of the unemployment rate and productivity growth is -0.7 ; the correlation between the short-run components in 0.3 . The authors show that these results are very robust to the choice of filtering technique. Of course, the fear that "this

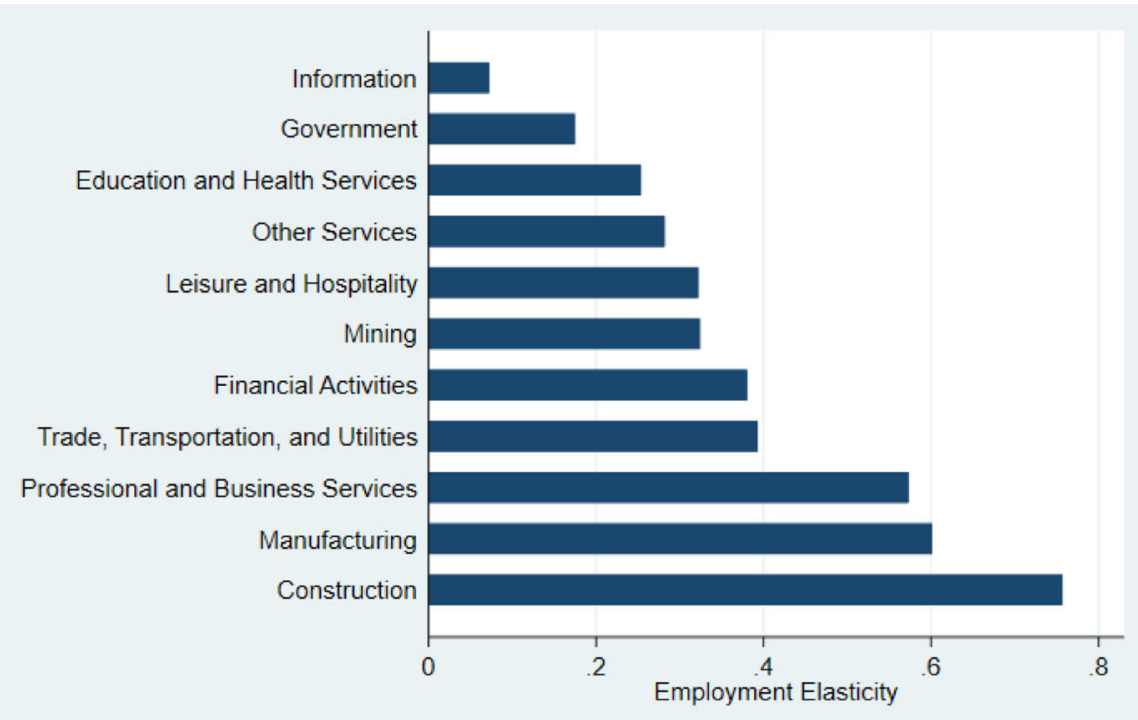

Fig. 4 Cyclical Sensitivity of Employment By Sector. Source: Gonzalez Prieto et al. (2018). The bars show the response of employment growth to output growth in U.S. industries 

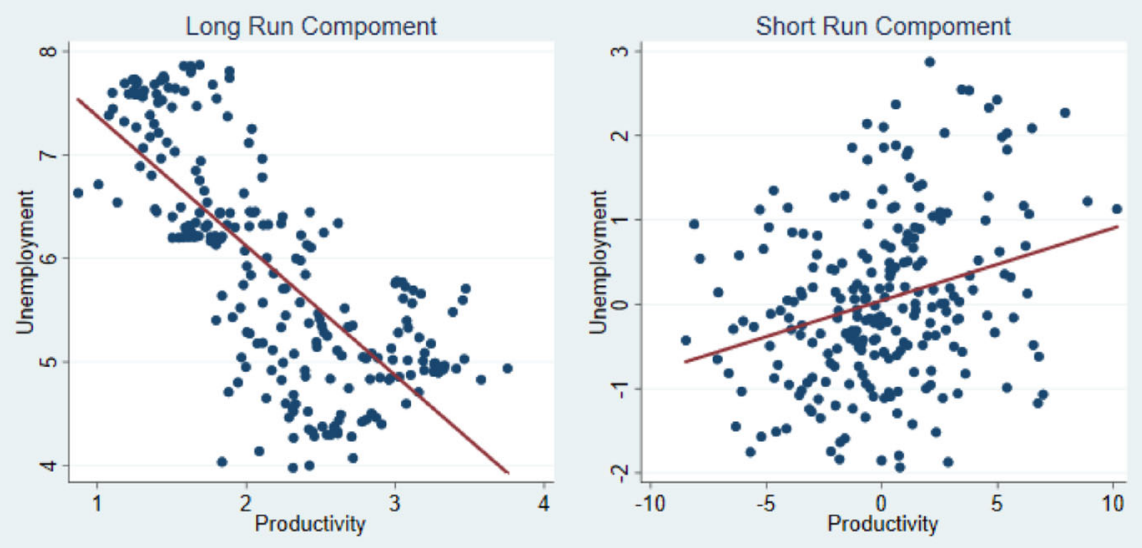

Fig. 5 Unemployment \& Productivity: Long-Run vs. Short-Run Relationship. Source: Chen and Semmler (2018)

time is different" cannot fully be erased by past correlations, but it would be unwise to completely ignore them as well.

\section{Structural Reforms to the Rescue?}

Structural reforms in product and labor markets are often put forward as a panacea for all that ails economies and labor markets. In product markets barriers to entry need to be eased in retail trade, professional services, and some segments of network industries. In labor markets, excessive provision of either employment protection or unemployment benefits impairs the micro-flexibility of labor markets - the ability of markets to reallocate workers to productive jobs). Moreover, since the effects of reforms in one area depend on reforms in other areas, often there is a call for a 'big bang' or 'reform wave' with reforms conducted in many areas simultaneously.

Have such reforms waves proved effective in the past? Adhikari et al. (2018; this issue) study six cases of well-known waves of reforms - those of Australia, Denmark, Ireland, the Netherlands, and New Zealand in the early 1990s, and Germany in the early 2000s. They use the synthetic control method, which measures the impact of reforms by assessing outcomes in the reforming country vis-à-vis a control group of similar countries that did not implement the reforms. Their results suggest that output in four of the six cases was higher as a result of the reform. The exceptions were Denmark and New Zealand, which in the latter case may have been because the reforms were implemented when macroeconomic conditions were particularly weak. The results for Germany suggest positive output effects from the so-called Hartz reforms, which created new types of temporary employment contracts, introduced additional wage subsidies, significantly cut unemployment benefits for the long-term unemployed, restructured the public employment agency, and strengthened activation policies more broadly.

To summarize, the papers in the special issue describe a labor market that, despite a cyclical recovery, faces a host of longer-run challenges: divergence in unemployment rates across countries (a problem when many of these countries belong to a currency 
union); well-known problems of duality in labor markets - differences between tradable and nontradable sectors and between formal and informal work; legacy effects of the global financial crisis; and the threat from automation and structural transformations.

\section{References}

Adhikari, B. R. Duval, B. Hu and P. Loungani, 2018, "Can reform waves turn the tide? Some case studies using the synthetic control method" Open Econ Rev (this issue)

Ahir, H. and P. Loungani, 2016, "Global house prices: time to worry again?" IMF blog, December 8

Brezis, E. and G. Brand, 2018, "Productivity gap between sectors and double duality in labor markets" Open Econ Rev (this issue)

Brezis E, Hellier J (2018) Social mobility at the top and the higher education system. Eur J Polit Econ 52(March):36-54

Chen P. and W. Semmler, 2018, "Short and long effects of productivity on unemployment," Open Econ Rev (this issue)

Ernst, E. and F. Saliba, 2018, “Are house prices responsible for unemployment persistence?,” Open Econ Rev (this issue)

Gonzalez Prieto, N., P. Loungani and S. Mishra, 2018, "What lies beneath: a sub-national look at Okun's law" Open Economies Review (this issue)

Hantzche, A., S. Savsek and S. Weber, 2018, "Labour market adjustments to financing conditions under sectoral rigidities in the euro area" Open Econ Rev (this issue)

International Jobs Report, 2017, OCP Policy Center (July 3, 2017)

Monfort, M. J. Ordonez and H. Sala, 2018, "Inequality and unemployment patterns in Europe: does integration lead to (real) convergence?" Open Econ Rev (this issue)

Petreski, M., 2018, "Is informal job experience of youth undermining their labor-market prospects in transition economies" Open Econ Rev (this issue)

Phillips P, Sul D (2007) Transition modeling and economic convergence tests. Econometrica 75:1771-1855

Stuart E, Samman E, Hunt A (2018) Informal is the new normal: improving the lives of workers at risk of being left behind. ODI Working Paper 530(January) 